\title{
A IDEIA TELEOLÓGICA DAS CIÊNCIAS E A TELEOLOGIA DA VIDA INTENCIONAL EM HUSSERL: O ENCONTRO DE MEDITAÇÕES CARTESIANAS COM INVESTIGAÇÕES LÓGICAS
}

\author{
THE TELEOLOGICAL IDEA OF THE SCIENCES AND THE \\ TELEOLOGY OF INTENTIONAL LIFE IN HUSSERL: THE MEETING \\ OF CARTESIAN MEDITATIONS WITH LOGICAL INVESTIGATIONS
}

\author{
Carlos Diógenes C. Tourinho ${ }^{1}$ \\ Recebido em: 06/2018 \\ Aprovado em: 11/2018
}

\begin{abstract}
Resumo: O presente artigo aborda o tema da teleologia na fenomenologia de Husserl. Dividido em três partes, o artigo enfoca: 1) a tese de que as ciências possuem sua própria teleologia: a ideia norteadora de se constituir como uma "ciência autêntica"; 2) o princípio metódico da evidência, sem o qual as ciências não obteriam conhecimento, não realizando tal ideia orientadora; 3) a teleologia inerente ao preenchimento intuitivo de atos intencionais significativos. Por fim, o artigo revela uma "unidade teleológica": o encontro da ideia norteadora das ciências em Meditações Cartesianas com a teleologia originária da vida intencional de Investigações Lógicas.
\end{abstract}

Palavras-chaves: Edmund Husserl; teleologia; ciência; conhecimento; evidência; intencionalidade.

\begin{abstract}
The present paper approaches the subject of the teleology in Husserl's phenomenology. Divided in three parts, the article focuses: 1) the thesis that the sciences have their own teleology: the guiding idea of being constituted as an "authentic science"; 2) the methodical principle of evidence, without which the sciences would not obtain knowledge, not realizing such guiding idea; 3 ) the teleology inherent to the intuitive fulfillment of meaningful intentional acts. Finally, the article reveals a "teleological unity": the meeting between the guiding idea of the sciences in Cartesian Meditations and the teleology originary of the intentional life in Logical Investigations.
\end{abstract}

Keywords: Edmund Husserl; teleology; science; knowledge; evidence; intentionality.

\section{Introdução}

É bastante conhecida a pretensão husserliana de fornecer, na famosa conferência de Viena, intitulada A crise da humanidade europeia e a filosofia (1935), um diagnóstico da

\footnotetext{
${ }^{1}$ Bacharel em Filosofia pela UFRJ. Mestre e Doutor em Filosofia pela PUC-Rio (Área de Concentração: Teoria do Conhecimento). Professor Associado I do Departamento de Filosofia da Universidade Federal Fluminense (UFF/Niterói-RJ) e do Programa de Pós-Graduação em Filosofia da Universidade Federal Fluminense (PFI UFF/Niterói-RJ). Membro do Núcleo de Sustentação do GT de Fenomenologia da Anpof. E-mail: cdctourinho@yahoo.com.br
} 
enfermidade espiritual vivida pelo homem europeu, no período do Entre Guerras. A consolidação do projeto de naturalização da "vida do espírito" fomentou, na formação da mentalidade europeia, um esquecimento daquilo que, aos olhos de Husserl, nos remeteria à "estrutura espiritual" (gestige Gestalt) da Europa, a saber: o surgimento da filosofia, enquanto uma nova forma cultural, na qual todas as ciências sistemáticas estariam incluídas enquanto suas ramificações (HUSSERL, [1935] 1976). Segundo o autor, esta nova forma cultural teria conduzido os homens, por meio de um novo tipo de posição (neuartige Einstellung), a um deslocamento do olhar de suas preocupações circunstanciais para "tarefas infinitas" (unendlicher Aufgaben), transformando-os, assim, na figura de um novo homem. Tais metas infinitas contempladas por este novo homem seriam tal como um telos espiritual (geistige Telos) a guiar esta nova humanidade, conferindo-lhe o sentido de uma evolução em direção a um polo eterno. Em meio ao cenário da crise, em tom de manifesto, Husserl não hesita em convocar este homem a reviver o que foi esquecido, fazendo renascer nele a experiência de uma "racionalidade efetiva" (wirklichen Rationalität) que, ao triunfar sobre a visão fática do mundo (inerente à doutrina do naturalismo), uma vez mais, uniria esta mesma humanidade, regenerando-a, ao reconduzi-la, através do ideal da razão filosófica, ao seu solo espiritual originário, no qual encontramos uma teleologia "nativa" (eingeborenen) à Europa que, por sua vez, abrigaria outras teleologias. É justamente sobre este ponto que o presente artigo concentra suas considerações.

Se Husserl não nos fornece, ao menos, na conferência de Viena, uma elucidação mais precisa de tais teleologias particulares inerentes ao telos espiritual do homem europeu, quatro anos antes, já no começo de Meditações Cartesianas, o autor elucida-nos os momentos constitutivos da "ideia teleológica geral” (allgemeine Zweckidee) de ciência, responsável por animar continuamente a atividade científica no alcance gradativo do conhecimento. A análise de tais momentos remete-nos, por sua vez, para uma teleologia mais originária, própria da vida intencional. Eis o momento no qual o começo de Meditações Cartesianas encontra-se com Investigações Lógicas, ao retomar o tema da distinção e síntese entre atos intencionais significativos e seus preenchimentos intuitivos. Tal encontro permite-nos notar que, ao tomar como ponto de partida o telos espiritual da humanidade europeia, o tema da teleologia em Husserl nos remete para a teleologia das ciências, cujos momentos constitutivos conduzem à teoria husserliana da evidência dos objetos e, por conseguinte, para uma teleologia mais originária, inerente à vida intencional.

Apoiando-se, fundamentalmente, nos $\S \S 4$ a 6 de Meditações Cartesianas, o presente 
artigo encontra-se dividido em três partes: a primeira aborda a concepção husserliana segundo a qual as ciências teriam uma teleologia própria que as guiaria: a de se constituir como uma “ciência autêntica" (echter Wissenschaft); a segunda concentra-se em torno do que Hussserl considera um "primeiro princípio metódico": a evidência (Evidenz, Einsicht) da presença da coisa visada à consciência, sem a qual as ciências jamais aspirariam algo de definitivamente válido nos juízos formulados acerca dos objetos; por fim, retomando um tema propedêutico de Investigações Lógicas, os referidos parágrafos salientam, ao retomar a teoria husserliana da evidência, o preenchimento intuitivo das intenções significativas. A terceira parte do artigo irá mostrar, em conformidade com a Primeira e a Sexta partes de Investigações Lógicas, que haveria uma teleologia originária dos preenchimentos intuitivos, inerente à vida intencional. A teleologia das ciências conteria a da vida intencional, revelando-nos, ao final, uma "unidade teleológica". Façamos, então, um exame mais detalhado das referidas camadas teleológicas na fenomenologia de Husserl.

\section{Sobre a "ideia teleológica" das ciências}

Uma análise breve da concepção husserliana de um telos espiritual da humanidade europeia, bem como das teleologias particulares que lhe são inerentes, nos faz passar do ideal da razão filosófica de contemplação de metas infinitas para as ciências que, como "regiões espirituais", consistiriam em ramificações da própria filosofia. Se Husserl não nos fornece, ao menos, em 1935, na famosa conferência de Viena, uma elucidação de tais teleologias, quatro anos antes, nos $\S \S 4,5$ e 6 de Meditações Cartesianas (1931), obra resultante das conferências proferidas pelo autor em Paris, em 1929, dedica-se à análise da ideia central (Leitidee) em torno da qual se moveria a atividade científica. As ciências teriam, para além de sua existência de fato, enquanto fenômeno de cultura (Tatsächlichkeit de Kultur), uma teleologia própria que as guiaria: a de pretender realizar, por um esforço contínuo, a ideia diretriz de se constituir como uma "ciência autêntica" (echter Wissenschaft), conforme salienta Husserl, no $§ 4$ da referida obra (HUSSERL, [1931] 1973). Não se trata, como assinala o autor, da formação do conceito de ciência através de uma abstração comparativa baseadas nas ciências fáticas, mas sim, de uma pretensão (Prätention) que tais ciências trariam consigo, sem que pudessem justificá-la através de sua própria existência enquanto fenômeno de cultura. E é justamente nesta pretensão para a qual Husserl nos chama a atenção que encontramos a ciência como ideia - "ideia de ciência autêntica" (Idee echter Wissenschaft). A atividade científica avança, por aproximações 
sucessivas, na obtenção do conhecimento, na demonstração de hipóteses. Todavia, se a ciência exerce, de tempos em tempos, a corrigibilidade de suas conjecturas, tal movimento converge, segundo Husserl, para aquilo que as ciências aspiram, em sentido verdadeiro e próprio (im wahren und echten Sinne), como um fim ideal: alcançar verdades "válidas uma vez por todas e para todos" (ein für allemal und für jedermann gültig) (HUSSERL, [1931] 1973, p. 53). Deste modo, afirma-nos o autor, no $\S 4$ de Meditações Cartesianas, a despeito de tal processo de corrigibilidade inerente à atividade científica, nada poderia impedir as ciências de viver ( "einzuleben”), por um esforço contínuo, o sentido do que aspiram, preservando uma ideia clara e distinta do fim almejado. As ciências desenvolvem-se, então, inclinadas à busca por maior exatidão e precisão, exibindo um estado corrente de realização, no qual tendem para o alcance de uma perfeição crescente, gradualmente realizada. Tal estado corrente de realização é, por conseguinte, algo "relativo" para a ciência, na medida em que os momentos alcançados tornam-se, enquanto "realizações parciais", objetivos intermediários (Zwischenziele) entre um estado que é menos e outro que é mais perfeito. Muito embora tal estado de realização corrente seja imperfeito (uma vez que é transitório), ele exibe certa perfeição, ainda que relativa ao momento presente vivido pela ciência. Este momento é, de qualquer modo, um estado mais completo que aquele que lhe precedeu, de modo que a perfeição alcançada no momento seguinte seria como que o telos para o qual a ciência tendeu em seu estado anterior. Assim, cada estado corrente de perfeição não seria, para as ciências, um estado "definitivo" de perfeição. Aquele que está por vir representa para o estado presente um terminus para o qual ele tende e em relação ao qual ele é definido como um "ponto de partida". Neste sentido, como nos lembra André Muralt (MURALT, 1974), cada momento de uma ciência é reciprocamente um terminus - portanto, uma perfeição a ser procurada - e um ponto de partida para um novo esforço científico. A ciência progride, deste modo, nos termos do autor: "de um ponto de partida para um telos e do telos para um ponto de partida, realizando uma perfeição crescente de exatidão e precisão" (MURALT, 1974, p. 13). Assim, guiadas por esta “ideia diretriz” para a qual Husserl nos chama a atenção, as ciências crêem superar o conhecimento ingênuo, bem como superar in infinitum a si próprias, conforme vivenciam, progressivamente, esta intenção (Intention) que, como uma tendência científica (wissenschaftlichen Streben), poder-se-ia dizer um "impulso vital", se torna responsável por animar continuamente suas realizações, guiando-as em sua tendência para a universalidade. Trata-se, nos termos de Paul Ricoeur, de se entregar à pretensão que anima as ciências a reviver (einleben) tal impulso, de “....realizar a ideia de ciência como correlato - o ‘noema' - desta intenção que anima o esforço científico” (RICOEUR, 1954, 
p. 78). Neste sentido, a ideia diretriz de se constituir como uma "ciência autêntica" torna-se o terminus final que polariza com o esforço científico, orientando-o para o conhecimento. Em suma, trata-se, segundo Husserl, de uma "ideia fim" (Zwecksinn, Zweckidee) do referido esforço, por meio do qual as ciências realizam ad infinitum tal ideia, em uma série convergente de aproximações assintóticas no curso do tempo. Tal como uma curva assintótica reúne a coordenada no infinito, a ideia em questão seria realizada no infinito. Tal desenvolvimento das ciências para um "absoluto mais absoluto" expressa, portanto, o dinamismo interno do conhecimento científico, cujo caminho aponta para um limite, ainda que, poder-se-ia dizer, nos termos de Muralt (MURALT, 1974), para um "limite infinito".

\section{A evidência como "primeiro princípio metódico"}

A análise dos momentos constitutivos desta "ideia teleológica geral" (allgemeine Zweckidee) para a qual convergem as ciências remete-nos para o impulso de reviver o alcance do conhecimento que, para Husserl, consiste na liberdade de "realizar de novo" (Wiederverwirklichung), de retornar novamente a uma justificação estabelecida ou verdade demonstrada (ausgewiesene Wahrheit) como "identicamente a mesma", fazendo dela própria uma aquisição, um bem definitivamente adquirido (HUSSERL, [1931] 1973). Tal impulso científico para a generalidade coloca-nos, por sua vez, diante daquilo que, aos olhos do autor, justificaria o sentido do conhecimento: a "evidência" (Evidenz, Einsicht). Em sentido o mais amplo, a evidência proporciona-nos, segundo Husserl, a experiência de um ser e da sua maneira de ser (Erfahrung von Seiendem und So-Seiendem). Nos termos de Husserl, no $§ 5$ de Meditações Cartesianas: "o olhar do nosso espírito alcança a coisa ela mesma" (Es-selbstgeistig-zu-Gesicht-bekommen) (HUSSERL, [1931] 1973, p. 52). Nela, a coisa intencionada não é apenas visada de forma distante ou "remota" (sachfernen), como objeto de uma intenção meramente significativa. Antes disso, a coisa visada nos é, de certo modo, presente "ela própria" ( sie selbst), em seu estado de coisa “ele próprio". Trata-se, portanto, do que Husserl considera um primeiro princípio metódico (erstes methodisches Prinzip), destinado a reger todos os passos ulteriores: a evidência da presença da coisa à consciência. Como lembra Husserl, ao asserir predicações sobre os objetos, a ciência não quer apenas formular juízos acerca dos mesmos, mas fundá-los na evidência, não podendo atribuir validade final (Endgültigkeit) a um juízo qualquer (nem tampouco atribuir ao juízo o valor de uma etapa intermediária no caminho que conduzisse à validade final) se não tiver extraído tal validade judicativa do que é evidente, 
quer dizer, nas palavras do autor, das experiências ("Erfahrungen") nas quais as coisas nos são apreendidas elas próprias (HUSSERL, [1931] 1973). Nos termos da Conferência de Paris (1929), da qual resultou, aliás, Meditações Cartesianas (1931), Husserl já nos chamava a atenção para a importância que o princípio de "julgar apenas em evidência" (nur in Evidenz zu urteilen) assume para a ciência em geral. Aspirando a um ideal de cientificidade, a ciência investe-se, alerta-nos o autor na referida conferência, de um intuito para o qual juízo algum deve ter valor de "conhecimento científico" (wissenschaftliche Erkenntnis) se não for fundamentado em plena evidência, quer dizer, se não puder se legitimar "pelo retorno às próprias coisas ou estados de coisas numa experiência e evidência originárias" (durch Rückgang auf die Sachen oder Sachverhalte selbst in ursprünglicher Erfahrung und Einsicht) (HUSSERL, [1929] 1973, p. 6).

$\mathrm{O}$ ato de julgar é uma intenção (Meinen) e, em geral, uma simples presunção (Vermeinen) de que uma coisa seja isso ou aquilo. Neste caso, o que é afirmado pelo juízo é apenas coisa ou estado de coisa presumido, ou ainda coisa ou estado de coisa visado (Sachverhalts meinung). Porém, eventualmente, deparamo-nos com outro julgar intencional (urteilendes Meinen), no qual temos, de certo modo, a consciência da presença do que é julgado, ou como gosta de dizer Husserl: a "efetiva doação das coisas" (die wirkliche Selbstgebung der Sachenreicht) (HUSSERL, [1931] 1973, p. 54). Trata-se, portanto, de ter à consciência isso e aquilo julgado (urteilend das und das bewußt Haben). Como salienta Paul Ricoeur (1954), o "valor de ser" do julgamento estaria diretamente ligado a este preenchimento intuitivo de uma intenção significante "vazia", preenchida pelo "pleno" de uma evidência, seja empírica ou categorial. Tal conversão de um mero julgar presuntivo (vermeinendes Urteilen) em um julgar intencional no qual a coisa julgada se faz, de certo modo, presente à consciência torna-se assegurada pela evidência da coisa "visada e autodada” (Gemeinte und Selbstgegebene). Dá-se uma conformação entre o ato de visar e seu preenchimento intuitivo. Esta passagem (Überführung) como tal possui o caráter de preenchimento de uma simples intenção vazia, fornecendo-nos, nos termos de Husserl, uma "síntese de conformação segura" (Synthesis der stimmenden Deckung). Ela é, em suma, uma evidente internalização (Innesein) da exatidão daquela intenção, antes distante da coisa visada e, portanto, daquela intenção não preenchida (unerfüllter Vormeinungen), inadequada (sachfernen) em relação à coisa visada. No entanto, alerta-nos o autor, a referida conversão pode permanecer no estado de simples "pretensão" (Prätention). Esconder-se-á, todavia, aí um fim ideal (ideales Ziel): o ideal que guia constantemente as ciências na sua tendência para a universalidade sistemática do conhecimento. 
A exigência segundo a qual o cientista não poderá aspirar a nada de definitivo se não fundar na evidência os juízos que formula será, segundo Husserl, sucedida por outra: a de refletir sobre o alcance e limite da própria evidência em questão, explicitando o grau de perfeição no qual uma coisa qualquer nos é efetivamente dada. Afinal, a perfeição ideal exigida pela evidencia diferencia-se, podendo ser, nos termos do autor, "mais ou menos perfeita" (mehr oder minder vollkommener). Temos perante nós uma infinidade de experiências ou evidências pré-científicas (Endlosigkeit der vorwissenschaftlichen Erfahrunden, Evidenzen). Referindo-se a esta nova exigência, Husserl afirma-nos que toda "evidência predicativa implica em uma evidência pré-predicativa" (Prädikative Evidenz schließt vorprädikative ein) (HUSSERL, [1931] 1973, p. 52). Quer dizer, implica, em última instância, em qualquer coisa visada, respectivamente, vista evidentemente e expressa. As ciências aspiram predicações destinadas a dar à intuição pré-predicativa (das vorprädikativ Erschaute) uma expressão completa e evidentemente adequada. E é justamente o princípio metódico da evidência que deverá reger esta tarefa. A evidência pré-predicativa supõe, por sua vez, no plano sensível, uma coisa visada, cuja presença à consciência assegura-nos a sua evidenciação. Em termos husserlianos, através da evidência da coisa visada, a intenção vazia preenche-se: tem-se um "preenchimento de significação" (Bedeutungserfüllung). Passamos de uma mera presunção (Vermeinen) do ato que intenciona a coisa visada para a presença (Gegenwart) intuitiva da coisa "ela mesma" à consciência. Eis, portanto, o momento no qual o texto de Meditações Cartesianas religa-nos a um tema central, apresentado já nos primeiros parágrafos de Investigações Lógicas: a distinção e síntese entre "intenção significativa" (Bedeutungs intention) e "intuição de preenchimento" (erfüllender Anschauung). Tal tema nos revelará, por sua vez, uma teleologia mais originária. Vejamos.

\section{A teleologia originária inerente à vida intencional}

As primeiras palavras de Husserl sobre tal distinção fundamental e sobre a referida síntese remetem-nos, de imediato, para duas passagens específicas de suma importância de Investigações Lógicas. No Segundo Volume (Parte I), o destaque é para o $§ 9$ do Capítulo 1 da Primeira Investigação, ao passo que, no Segundo Volume (Parte II), publicado na segunda edição de 1913 como um volume a parte, a ênfase recai sobre o $§ 16$ do Capítulo 3 da Sexta Investigação.

Inicialmente, apoiando-se no $\S 9$ do Capítulo 1 da Primeira Investigação, deparamo-nos 
com o que poderíamos considerar uma "dupla união" inerente às "sínteses de preenchimento" (Erfüllungssynthesen). A primeira união consiste já na fusão entre o signo em seu aspecto físico (o signo sensível, o complexo fônico articulado, etc.) e os atos que lhe dão significação, tornando, assim, um som de palavra "animado de sentido" (sinnbelebter Wortlaut). Na medida em que apenas visam o objeto, tais atos significativos - inicialmente "vazios", em termos intuitivos - se tornam, eventualmente, "preenchidos" pela presença do objeto visado, realizando, com isso, a sua referência objetiva. Eis a segunda união. Tais uniões formam, segundo Husserl, uma "unidade intimamente fundida" (eine innig verschmolzene Einheit) e somente a análise ou desmembramento de uma expressão animada de sentido e preenchida intuitivamente poderá revelar tais atos que se fundem na "expressão completa" (vollen Ausdruck), em seus aspectos: sensível, significativo e intuitivo ${ }^{2}$.

Deparamo-nos, na passagem da mera "presunção" do ato de visar à "presença" da coisa visada à consciência, com uma camada teleológica mais originária. Husserl chama-nos a atenção, no caso da percepção, para os graus sucessivos de preenchimento intuitivo dos atos intencionais, nos quais a evidência diferencia-se, assegurando o aclaramento gradativo do objeto visado (HUSSERL, [1901] 1913). No $§ 16$ do Capítulo 3 da Sexta Investigação, Husserl salienta que, em cada preenchimento de atos significativos, encontramos um "tornar-se intuitivo" que, por sua vez, é "mais ou menos" completo (mehr oder minder vollkommene). Husserl mostra-nos, especificamente, no caso da percepção de um objeto, que tal preenchimento impõe-nos gradações, algo da ordem de uma relação de "aumento", uma vez que, ao atribuir "plenitude" ("Fülle”) ao ato, este tornar-se intuitivo assegura a presença daquilo que é visado pelo ato significativo, mas esta presença se faz, gradativamente, em uma série de preenchimentos que aumentam progressivamente o conhecimento do objeto, em termos de vivacidade ou riqueza do que é intencionado, confirmando, com isso, em gradações ou níveis crescentes, a realização (ou atualização consciente) da referência objetiva. O autor apresentanos, ao final do $\S 16$ da Sexta Investigação, um exemplo desta série ascendente de preenchimento (Steigerungsreihen der Erfüllung). O exemplo mostra-nos a passagem de um grosseiro desenho apenas esboçado para um desenho a lápis realizado com mais exatidão. Em seguida, a passagem deste desenho a lápis para uma imagem mais nítida, chegando até a realização de uma pintura com maior vividez. Por fim, a passagem para a presença do mesmo objeto. Nos termos do autor: "visivelmente o mesmo" (HUSSERL, [1931] 1973). Se tais atos

\footnotetext{
${ }^{2}$ Para uma análise mais aprofundada da "dupla união" inerente às sínteses de preenchimento (Cf. Tourinho, C. D. C. "Sobre a adequação entre intenção significativa e preenchimento intuitivo nas Investigações Lógicas de Husserl", pp. 361-374).
} 
intencionais significativos aspiram a um preenchimento intuitivo, cada grau de preenchimento aspiraria, por sua vez, a um "ideal de preenchimento definitivo" (Ideal der letzten Erfüllung), tendo como fim a "perfeição da adequação" (Vollkommenheit der Adäquation) entre o ato intencional significativo e seu preenchimento intuitivo. Cada grau de preenchimento seria mais ou menos perfeito. Aqui, imperfeição (Unvollkommenheit) equipara-se à incompletude (Unvollständigkeit). As evidências imperfeitas são unilaterais, relativamente obscuras, além de indistintas quanto ao modo pelo qual as coisas nos são dadas elas mesmas (Selbstgegebenheit). Enquanto aspira por uma perfeição ideal, a experiência encontra-se viciada por componentes da intenção significante que não foram preenchidos (unerfüllter Vormeinungen) ainda por uma intuição correspondente. O aperfeiçoamento opera-se, então, numa "progressão sintética" (synthetischer Fortgang) de experiências concordantes (einstimmiger Erfahrungen), onde essas intenções significantes se elevam ao estádio de experiência efetiva (wirklichen Erfahrung) que as confirma e as preenche. Em tal série de preenchimentos, tratar-se-ia, portanto, de uma camada teleológica inerente à vida intencional, de uma "teleologia de realização" (SHÉRER, 1969), ou ainda de uma "tendência intencional" (MURALT, 1974). Neste sentido, poder-se-ia dizer, nos termos de André Muralt, que: "Intencionalidade é teleologia" (MURALT, 1974, p. 27). O mesmo autor salienta-nos ainda que todos os momentos de realização do desenvolvimento da ciência encontram-se envolvidos com uma teleologia intencional (MURALT, 1974). Se o telos espiritual da humanidade europeia contém a ideia diretriz que une as ciências, conforme afirma-nos Husserl na década de trinta, no período de consolidação das reflexões do autor sobre a crise vivida pela humanidade europeia, tal ideia remete-nos, por sua vez, para uma teleologia mais originária que lhe é própria, ligando, deste modo, os §§ 4-6 de Meditações Cartesianas a um conteúdo propedêutico à fenomenologia husserliana, apresentado desde o início da Primeira Investigação de Investigações Lógicas.

\section{Conclusão}

A análise dos momentos constitutivos da ideia teleológica geral de ciência remete-nos, então, conforme vimos, para uma teleologia mais originária, inerente à vida intencional, revelando-nos o encontro dos primeiros parágrafos de Meditações Cartesianas com um conteúdo propedêutico apresentado por Husserl já na primeira edição de Investigações Lógicas, em 1901. Se no período de consolidação das reflexões sobre a crise da humanidade europeia, Husserl nota, no ideal da razão filosófica de contemplação de metas infinitas, o telos espiritual 
do homem europeu, não explicita, contudo, no mesmo período (especificamente, na conferência de Viena), o sentido das chamadas "teleologias particulares" inerentes à realização de tal ideal. Da filosofia, ramificam-se, sistematicamente, diferentes domínios científicos, conforme Husserl nos lembra na famosa conferência de 1935. Mas, tal como vimos, o autor esclarecenos, quatro anos antes, nos $\S \S 4$ a 6 de Meditações Cartesianas, que tais domínios unem-se, por um esforço contínuo, em torno do ideal das ciências de se constituir como uma "ciência autêntica" (echter Wissenschaft), aspirando o alcance de verdades "válidas uma vez por todas e para todos" (ein für allemal und für jedermann gültig). Neste sentido, as ciências aproximamse, assintoticamente, de tal constituição, na medida em que elas mesmas avançam, conforme obtêm o conhecimento, cujo sentido justifica-se, segundo Husserl, pela evidenciação dos objetos à consciência. Como salienta Paul Ricoeur (RICOEUR, 1954), esta "ideia fim" (Zweckidee) das ciências se tornaria estéril se ela não fosse diferenciada por uma "teoria da evidência" que, por sua vez, repete os temas fundamentais de Investigações Lógicas. Sendo assim, nos termos do autor, no que concerne à teoria em questão, não somente é preciso admitila, mas admiti-la "antes de começar e para começar" (RICOEUR, 1954, p. 79). Uma vez que os conceitos de "evidência" (Evidenz, Einsicht) e de "intuição" (Intuition, Anschauung) encontram-se, em Husserl, indissociavelmente, relacionados, tal evidenciação supõe a distinção e síntese entre uma vivência intencional e o seu preenchimento intuitivo, tanto no âmbito de uma evidência predicativa (ou categorial) quanto no âmbito de uma evidência pré-predicativa (ou sensível). Posto que a primeira supõe a segunda, considerando que, no plano sensível, conforme Husserl nos chama a atenção no $§ 16$ da Sexta Investigação, os preenchimentos intuitivos do objeto visado significativamente se realizam gradativamente, aspirando a uma perfeição de adequação, deparamo-nos, como vimos, com uma realização teleológica própria da vida intencional. Trata-se, portanto, de uma camada teleológica mais originária. Se do ideal da razão filosófica de contemplação de metas infinitas ramificam-se as ciências que, por sua vez, unem-se em torno de uma mesma “ideia fim”, a realização de tal ideia faz-se, gradativamente, conforme as ciências avançam na obtenção do conhecimento que, como tal, inevitavelmente, remete-nos, aos olhos de Husserl, para uma realização teleológica própria da vida intencional. Husserl aponta-nos, então, poder-se-ia dizer, três "camadas teleológicas". A camada geral do ideal da razão filosófica como telos espiritual do homem europeu, conteria uma camada intermediária dos diferentes domínios científicos (unidos pela ideia teleológica geral das ciências de se constituir como uma "ciência autêntica") que, por sua vez, abrigaria uma camada mais originária referente à realização teleológica da vida intencional. Tais camadas 
encontrar-se-iam unificadas, revelando-nos uma "unidade teleológica". Nela, deparamo-nos com a doutrina das intenções significativas e dos seus preenchimentos intuitivos, na própria exposição da doutrina da teleologia das ciências, atestando-nos, assim, um encontro legítimo da teoria das evidenciações apresentada em Investigações Lógicas com o começo radical de Meditações Cartesianas. Tal encontro levar-nos-ia, inevitavelmente, a uma teleologia mais originária na qual encontraríamos talvez o sentido mais íntimo da fenomenologia husserliana, sem o qual conhecimento algum se tornaria possível: a presença intuitiva da coisa visada, a evidenciação dela mesma à consciência, revelando-se, em sua totalidade, como "fenômeno".

\section{Referências Bibliográficas}

HUSSERL, E. Logische Untersuchungen. Zweiter Band. Teil I. "Untersuchungen zur Phänomenologie und Theorie der Erkenntnis". Stuttgart, Tübingen: Max Niemeyer Verlag, ([1901] 1913b, 1968).

Logische Untersuchungen. Zweiter Band. Teil II. "Elemente einer phänomenologischen Aufklärung der Erkenntnis". Stuttgart, Tübingen: Max Niemeyer Verlag, ([1901] 1913c, 1968).

. Cartesianische Meditationen und Pariser Vorträge. Husserliana (Band I). Den Haag, Netherlands: Martinuos Nijhoff, ([1931/ 1929] 1973).

. "Die Krisis des europäischen Menschentums und die Philosophie". In: Die Krisis der europäischen Wissenschaften und die transzendentale Phänomenologie. Husserliana. Band VI. Netherlands: Martinus Nijhoff, ([1935] 1976).

MURALT, A. The Idea of Phenomenology: Husserlian Exemplarism. Evanston: Northwestern University Press, 1974.

RICOEUR, P. "Etude sur les 'Méditations Cartésiennes' de Husserl”. In: Revue Philosophique de Louvain. Tome 52, Série, $n^{\circ}: 33$. 1954; pp. 75-109.

SCHÉRER, R. La Fenomenología de las "Investigaciones Lógicas" de Husserl. Biblioteca Hispánica de Filosofía. Madrid: Editorial Gredos, 1969.

TOURINHO, C. D. C. "Sobre a adequação entre intenção significativa e preenchimento intuitivo nas Investigações Lógicas de Husserl”. In: Cognitio: Revista de Filosofia. Volume 16, número 2 (julho/dezembro de 2015), pp. 361-374. 